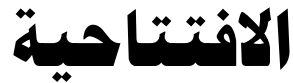

\section{هصر.. في قلب آسيا وأفريقيا وأوروبا}

\section{بقايم \\ ضياء رشوان \\ رئيس الهيئة العامة للاستعلامهات}

خلال ثلاثة شهور (فبراير - مارس - أبريل 9 أب ب) أعادت مصر تأكيا إحدى البديهيات الجغر افية والاستر اتيجية المعروفئسة

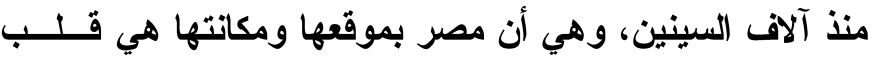

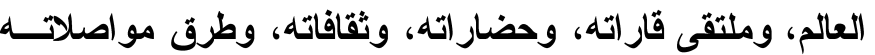

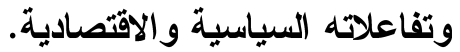
هكذا كانت مصر طوال تاريخها، لـ يمنعها عن الاضــــــلاع

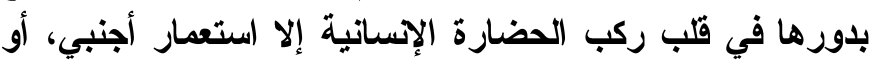

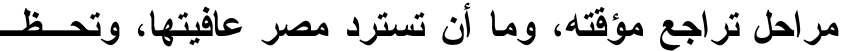

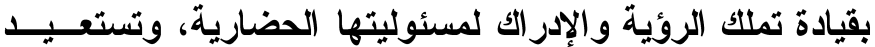
الثقة في ذاتها، إلا وتبادر تحمل هذه المسئولية وتنطلق لأدائهـــا في كل الاتجاهات. هذه الحقيقة تجسدت في التحرك السياتسي و الابلوماسي رفيع المستوى الأي قامت به مصر خلال الثهور الثلاثة.

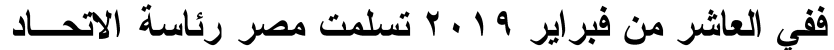

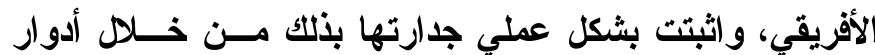

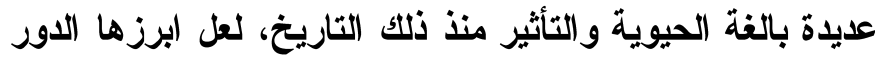

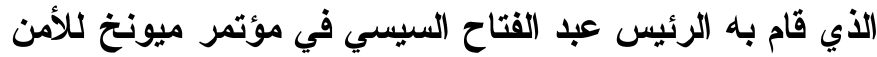

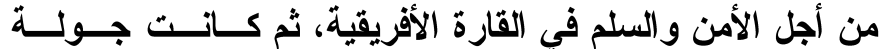

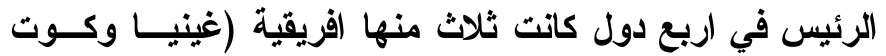

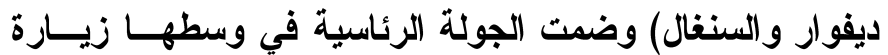
للولايات المتحدة الأمريكية لم تغب عنها أيضاً القضايا الأفريقية.

آفاق آسيوية آفات آسيوية آفات آسيوية آفية آفيوية

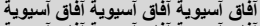

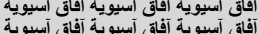

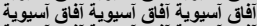

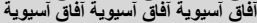

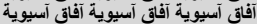
آفاق آسيوية آفاتق آسيوية آفاتق آسيويةية

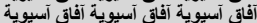

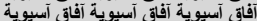

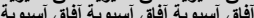

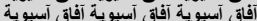

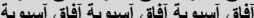

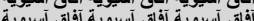

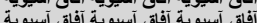

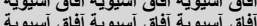

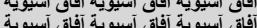

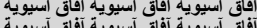

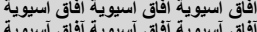

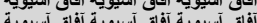

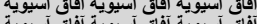
آفاق آسيوية آفاتق آسيوية آفاق آسيوية آفيوية آفيوية آفاق آسيوية آفاق آسيوية آفاق آسيوية آسية آسيوية

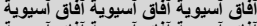

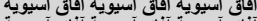

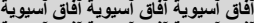

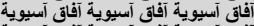

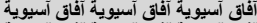
آفاق آسيوية آفاقي آسيوية آفاقي آسيوية آسيوية آفاقَ آسيوية آفاتق آسيوية آفائ آسيويةية آثيوية

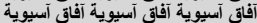

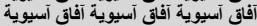

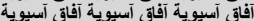

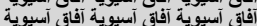

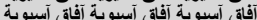

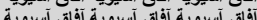

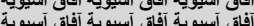

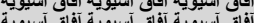

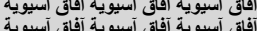

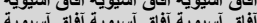

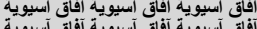

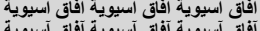

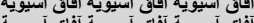

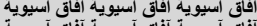

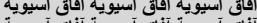
آفات اسيوية آفات اسيوية آفات اسبيوية آسيوية آفاق آسيوية آفاق اسيوية آفاق آسيوية آسيوية

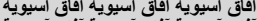
آفاق آسيوية آفات آسيوية آفاق آسيوية آسية آفاق آسيوية آفاتى آسيوية آفاق آسيوية آتية آفاق آسيوية آفاق آسيوية آفاق آسيوية آتيوية آفاق آسيوية آفاتق آسيوية آفات آسيوية آثيرية

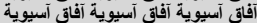

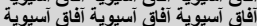

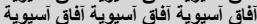

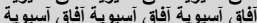

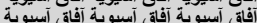

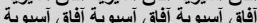

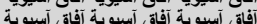

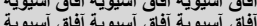

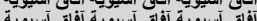

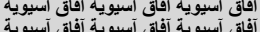

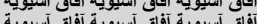

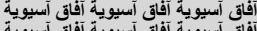

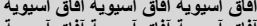

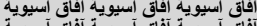

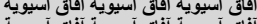
آفات آسيوية آفاتق آسيوية آفات آسيوية آسية آفاق آسيوية آفالق آسيوية آفاق آسيوية آسيوية آفاق آسيوية آفات آسيوية آفات آسيوية آثية آفاق آسيوية آفات آسيوية آفاق آسيوية آثية آثيوية آفاق آسيوية آفاقي آسيوية آفاتئ آسيوية

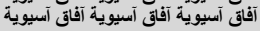




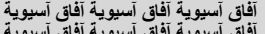

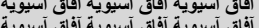

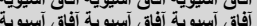

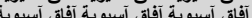

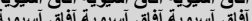

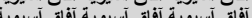

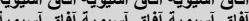

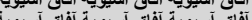

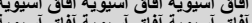

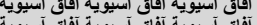

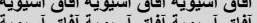

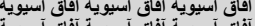

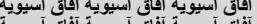

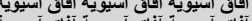
آفاقي آسيوية آفاق آسيوية آفيولية آسيوية آسيوية

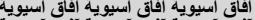
آفاق آسيوية آفات آسيوية آفاتئ آسيوية آسية آفاق آسيوية آفاق آسيوية آفاق آسيوية آسيوية

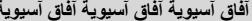
آفات آسيوية آفاق آسيوية آفاتق آسيوية آسيوية آفاق آسيوية آفاق آسيوية آفاتق آسيوية آسيوية

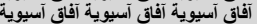

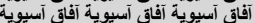

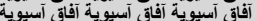

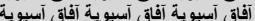

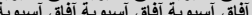

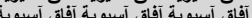

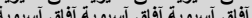

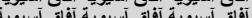

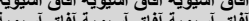

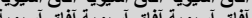

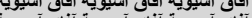

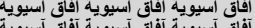

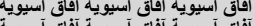

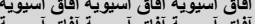
آفاق اسبوية آفاق آسيوية آفاتق آسيوية آسيوية

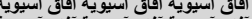

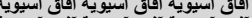
أفاق آسيوية آفات آسيوية أفاق اسيوية أسيوية آفاق آسيوية آفاق آسيوية آفاتى آسيوية آسيوية آفاق آسيوية آفاق آسيوية آفاق آسيوية آسيوية

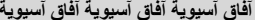

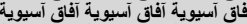

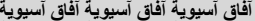
آفاتق آسيويةية آفاق آسيويةية آفاتئ آسيويةية

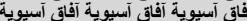

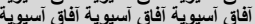

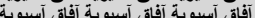

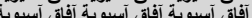

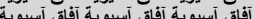

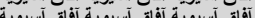

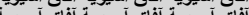

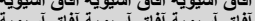

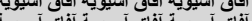

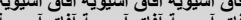

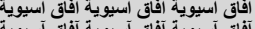
آفاق آسيوية آفأق آسيوية آفاتق آسيوية آسيوية

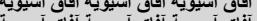
آفاق اسيوية آفاق آسيوية آثاتق آسيوية آسيوية

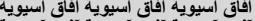
آقاق آسيوية أفاق آسيوية آفات آسيوية آسيوية آفاق آسيوية آفات آسيوية آفائ آسيوية آسية آثات آسيوية آفات آسيوية آفاتئ آسيوية آسية

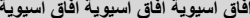

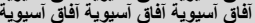

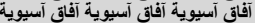
آفاق آسيوية آفاق آسيوية آثاتية آسيوية آسيوية

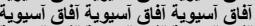

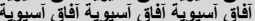

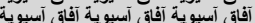

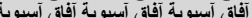

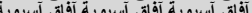

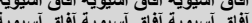

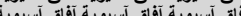

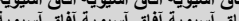

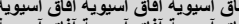

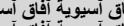

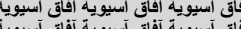

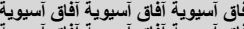

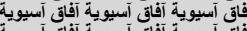

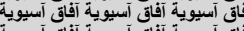
آفاق آسيوية آفاق آسيوية آفاقي آسيويية آسيوية
ثم في الرابع و العشرين من ابريل 9 1 ـ ب استضافت مصسر

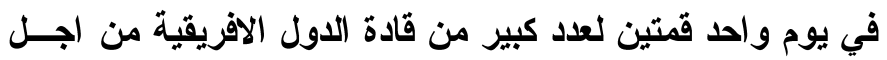

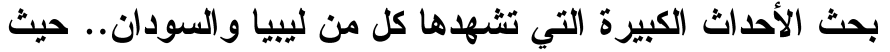

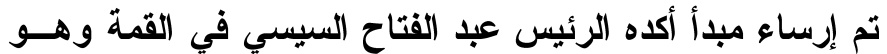

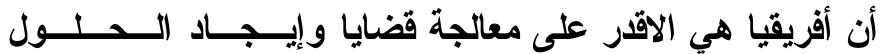

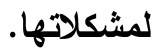

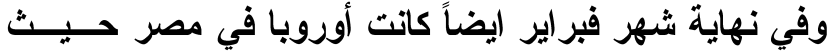

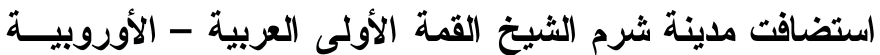

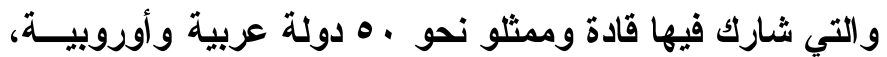

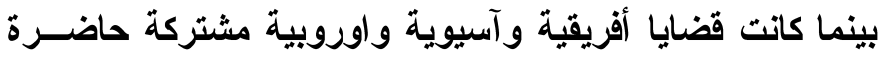

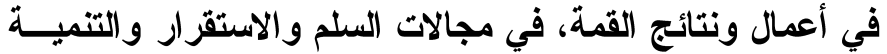

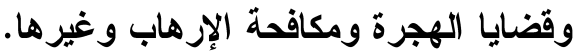

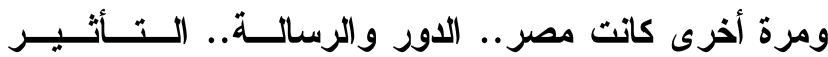
و الحيوية، هي المحرك من أجل المصالح المشتركة و المتلاقيـــة و المتقاطعة بين القار ات الثلاث.

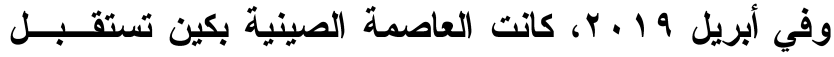

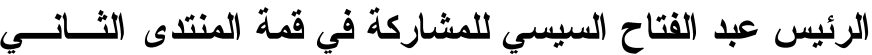

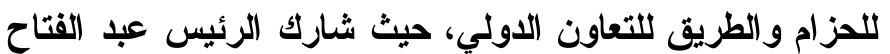

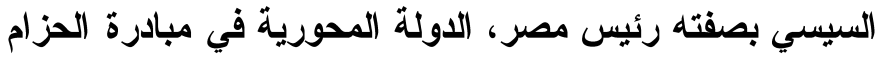

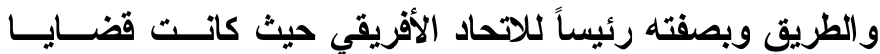

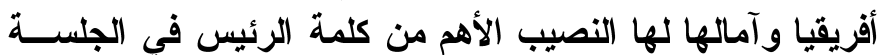

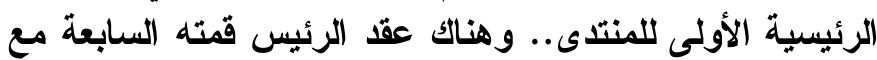

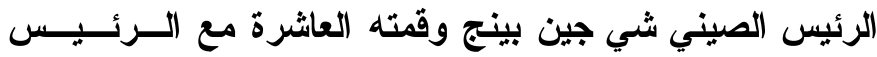
الروسي فلاديمير بوتين.

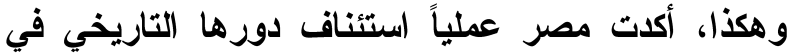

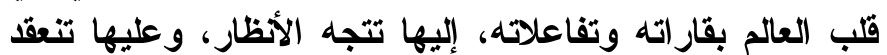

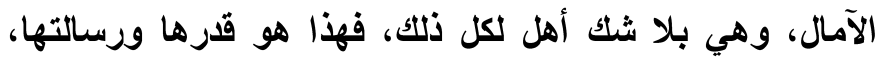
وبها يتحقى أمنها ومصالحها ورخاؤها. العدد الرابع - ابريل 9 ا ـ 